\title{
Numerical analysis and measures for the evaluation of comfort inside buses used for public transport
}

\author{
R. de Lieto Vollaro, S. Grignaffini \& A. Vallati \\ Technical Physics Department, University "La Sapienza", \\ Via Eudossiana, 18, 00184 Rome, Italy
}

\begin{abstract}
This work analyses the thermo hygrometric conditions inside buses used for public transport. The technical solutions, found through the analysis of the thermo hygrometric conditions inside trains, were also set out and extended to buses. This was in order to maximize the conditioning system and the installation of the air distribution terminals. A pattern for the simulation of the thermo fluid dynamics has been researched, in order to evaluate possible improvements in the conditioning system or in the distribution system. The summer time is the most critical period in the year for public transport. This fact is due to the frequent opening of doors, which makes the internal temperature uneven, due to the strong air drafts. It is also important to assess the cooling transition, which can often be long and unbearable for passengers inside. The simulation pattern, produced with Airpack 2.1 (Fluent) software, was then validated with a series of measures and used for the analysis of the main issues concerning discomfort. It was also used for the finalization of the improvements. This assessment addresses the fundamental problem that takes place at a bus stop when passengers exit and enter. It has been compared to the solution studied for installing doors equipped with air screens (or air screened doors). The thermo fluid dynamic results guarantee a significant improvement in thermo hygrometric comfort.
\end{abstract}

Keywords: comfort, buses, numerical analysis.

\section{Introduction}

Today a large number of people spend a lot of time inside the public transport system. Due to serious traffic conditions in big cities the use of these means is 
increasingly more frequent. The idea of conditioning the air inside public transport comes from the need to improve the well being of the people who use it daily to move within the city; as a matter of fact, the internal thermo hygrometric conditions are an important factor for the comfort and health of passengers and for the safety of drivers. This is the reason why the car industry has lately developed the feature of thermic comfort inside vehicles; the system has, at the same time, the aim of safeguarding the health of passengers and driver.

The issues of comfort in the environment inside the vehicle are extremely complex, because inside, air speed and temperature gradients are strong. Furthermore, the conditions during the cooling and heating transitions are severe. To this it must be added that the radiation phenomenon inside the vehicle, especially in the summer time, is very important. The basic hypotheses on which the mathematical pattern is built, are the thermal balance of the human body and the external uniform conditions. However these factors don't occur on buses.

So, some mathematical patterns which rule the energetic balance in transitioning conditions therefore human body thermal comfort index, were found in literature: for example, Taniguchi et al. [1] developed a linear multiple regression model, which evaluates thermal sensation. Such model hypothesizes supports the fact that passengers thermal sensation in one vehicle, depends not only on the superficial temperature of the skin of the face. It also depends on the derivative in correlation with the weather and its variations.

It is quite difficult to ensure a high level of air conditioning on public transport, where the doors frequently open outwards allowing passengers to exit and to enter the vehicle. Generally, for the heating system in the winter time, the most common system in use is the channeled electric resistance one; while in the summer time cooling system is realized with a direct expansion structure and a direct correlation of the refrigerating compressor system with the engine of the bus. The air distribution occurs through channels placed on top of the bus. In the case of urban buses, the air diffusion terminals are made with side gaps in the grid ceiling of the motor vehicle. In general, in the air conditioning of public means, the air input in the environment happens using the grid ceiling, as well as in the air recovery system. The aim of this study is that of building a simulation pattern, which when properly calibrated, would allow the effective analysis the of the air distribution system used today. It would also obtain new thermo fluid dynamic solutions.

\section{Numerical analysis}

The mathematical model, implemented for the optimization of the air distribution system, inside the compartment of a bus, was built using the numerical analysis simulation software (Airpack 2.1).

The CFD, Computational Fluid Dynamics, identifies the method, which, through numerical algorithms, leads to the equations solution, which models the laminar, or a fluid's turbulent motion, and of the related thermo dynamics processes.

The modeled thermo dynamics processes, which differ as application methods vary, refer to the heat transmission in all its forms. Also to the diffusion and the 
transport of inert and reagent substances, evaporation and condensation and the homogeneous and heterogeneous combustion. The calculation method formal refinement determined the times and places of CFD, development as an analytical instrument in the engineering field. Having said that, the aim of the research was the characterization of the bus thermo fluid dynamic behavior. Where the environmental conditions of comfort are reached through different systems of mechanical ventilation. The cases in study evaluated the influence of comfort, according to the speed field, which is both due to natural convention phenomena and to possible imposed air flows. Thus, the influence of these features on the ventilation system and on the thermo fluid dynamic side conditions has been considered. This work has demonstrated that the usage of a CFD code provides basic project inputs, with low economic and time requirements. The comfort can thus be foreseen, building guidelines that are mostly useful in the early stages of the system designation, enhancing the reduction in energy consumption and improving people's wellbeing.

The numerical model of the thermo fluid dynamic phenomenon has been carried out employing a continuous model. The air motions have been described by a system of various equations, to the non linear partial derivative that includes:

1. equation of mass conservation

2. balance equation of the motion quantity

3. balance equation of energy

4. state equation

In order to reach a solution though, the value of field variables have to be known in an instant; furthermore, the conditions aimed at representing the interaction between the motion field and the surrounding environment have to be assessed under the calculative point of view. It has implemented the follow boundary conditions: to evaluate the thermo dynamics aspects of the openings it has chosen a surface with constant pressure and to evaluate the walls of the bus it has chosen a surface with constant value of the temperature.

In this way we have studied the problem in stationary conditions.

As the continuous formulation model is chosen the discontinuation procedure draws on spatial derivatives of the field variables. This is done in each knot, with the algebraic value functions, the knot at issue and the adjacent knots. The discontinuation method analyzed in this study is the finite element method.

As far as turbulence is concerned, the characteristics of which are determined by the kind of flow in which they develop, the simulations have been carried out under a phenomenological point of view. Thus, a procedure introduced by Reynolds for uncompressible flows and then, generalized by Favre to compressible flows has been followed; the dependent variables in a turbulent situation are broken down in sums of average time value and fluctuation in comparison to that value.

The calculation procedure includes the solution grid's choice and the numerical algorithms of integration and also the definition of the convergence criteria and the adoption of a proper calculation instrument. In particular, the numerical analysis of turbulent flows requires the transformation of the equation variables' system (continuous mathematical model), into a system of algebraic 
relations (the discontinuous mathematical model). In order to perform a simulation, it is necessary to generate a wide stitched grid that leads to a quick solution and to the results of the forwarded hypotheses; afterwards, it is necessary to tighten the grid so as to increase the solution's resolution and accuracy. The tightening of the grid is necessary in the regions of the calculative domain where there are strong gradients of field variables. This is in order to avoid an unrealistic result at a local and global level. The motion equations of the algebraic forms applied for each knot form, is a system of simultaneous equations in the field variables for all the knots of the grid; in the cases studied an implicit algorithm is being employed.

A CFD code aimed at the analysis of air flows in closed environments and of the effects they lead to, must be able to foresee:

- thermal comfort of the occupants;

- efficiency and effectiveness of thermal energy distribution systems in the vehicle;

- effectiveness of ventilation systems in removing or controlling the distribution of temperature and speed variables.

Pursuing the indicated objectives requested is necessary to identify the reference geometry of the functioning conditions of the single system. As well as the thermic features of the surfaces that build the case in study. In particular, the variation intervals of temperature and speed variables, as well as the type and distribution of thermo fluid dynamic inside and outside the vehicle, derive from the project optimization criteria.

\section{Present situation analysis}

This work has been developed through different phases. In the first phase, the mathematical method, for the numerical assessment in the thermo fluid dynamics field, was implemented inside buses chosen for the study of comfort conditions.

In the second phase, some experimental measures were applied inside buses. Such measures were then used to validate the implemented model.

It shows some exemplifying tables, chosen two representative intervals of time in the warmest hours of a summer day of the July 2005; it has analyzed the intervals in which the outside temperature was nearly the temperature of $30^{\circ}$ which is the value implemented in the simulation, to confront the data obtained and the data measured in the most correct way.

In the third phase, the problems that lead to discomfort conditions inside buses have been identified. The system's possible modifications have been studied in order to improve the climate conditions inside buses. In the fourth stage a numerical simulation has been performed using the system solutions identified. In the simulations made with Airpack software it has neglected the thermal effects of the engine and it has analyzed the aspects concerned the fluidodynamic system studying the air conditioning plant and the thermal comfort inside the vehicle. Finally, some interesting conclusions were reached. They would, however, have to be developed in order to become operational on buses. As far as the real validation of the model is concerned, tables 1-4 
Table 1: $\quad$ Vehicle in gear with closed doors.

\begin{tabular}{|c|c|c|c|c|}
\hline & $\begin{array}{c}\text { Average } \\
\mathrm{T}\left({ }^{\circ} \mathrm{C}\right)\end{array}$ & $\begin{array}{c}\text { Average } \\
\text { Speed } \\
\mathrm{V}(\mathrm{m} / \mathrm{s})\end{array}$ & $\begin{array}{c}\text { Standard } \\
\text { Deviation T }\end{array}$ & $\begin{array}{c}\text { Standard } \\
\text { Deviation } \\
\mathrm{V}\end{array}$ \\
\hline POINT 1b & 27.2 & 0.3 & 1.1 & 0.79 \\
\hline POINT 2b & 28.9 & 0.3 & 2 & 1.7 \\
\hline POINT 3b & 27.6 & 0.5 & 1.3 & 1.3 \\
\hline POINT 1a & 28.5 & 0.9 & 1.9 & 0.98 \\
\hline POINT 2a & 27.5 & 1.1 & 1.94 & 2.7 \\
\hline POINT 3a & 27 & 1.3 & 1.99 & 3.1 \\
\hline & & & & \\
\hline
\end{tabular}

Table 2: $\quad$ Vehicle at a stop with open doors (30 seconds).

\begin{tabular}{|c|c|c|c|c|}
\hline & $\begin{array}{c}\text { Average } \\
\mathrm{T}\left({ }^{\circ} \mathrm{C}\right)\end{array}$ & $\begin{array}{c}\text { Average } \\
\text { Speed } \\
\mathrm{V}(\mathrm{m} / \mathrm{s})\end{array}$ & $\begin{array}{c}\text { Standard } \\
\text { Deviation T }\end{array}$ & $\begin{array}{c}\text { Standard } \\
\text { Deviation V }\end{array}$ \\
\hline POINT 1b & 25.1 & 0.2 & 1.17 & 2.1 \\
\hline POINT 2b & 28.4 & 0.3 & 0.9 & 1.16 \\
\hline POINT 3b & 27.2 & 0.5 & 1.23 & 1.57 \\
\hline POINT 1a & 26.8 & 0.7 & 1.89 & 1.67 \\
\hline POINT 2a & 26.1 & 0.9 & 0.94 & 1.12 \\
\hline POINT 3a & 25.9 & 1.1 & 0.99 & 1.98 \\
\hline
\end{tabular}

Table 3: $\quad$ Gap between experimental and simulated values (closed doors).

\begin{tabular}{|c|c|c|}
\hline & TEMPERATURE Gap (\%) & SPEED Average Gap \\
\hline POINT 1b & $3 \%$ & 0.8 \\
\hline POINT $2 \mathrm{~b}$ & $3 \%$ & 0.8 \\
\hline POINT 3b & $4 \%$ & 0.3 \\
\hline POINT 1a & $3,5 \%$ & 0.3 \\
\hline POINT 2a & $3 \%$ & 0.4 \\
\hline POINT 3a & $5 \%$ & 0.65 \\
\hline
\end{tabular}

Table 4: $\quad$ Gap between experimental and simulated values (open doors).

\begin{tabular}{|c|c|c|}
\hline & TEMPERATURE Gap (\%) & SPEED Average Gap \\
\hline PUNTO $1 \mathrm{~b}$ & $1 \%$ & 0.1 \\
\hline PUNTO $2 \mathrm{~b}$ & $1 \%$ & 0.3 \\
\hline PUNTO $3 \mathrm{~b}$ & $2 \%$ & $/$ \\
\hline PUNTO $1 \mathrm{a}$ & $6 \%$ & 0.6 \\
\hline PUNTO $2 \mathrm{a}$ & $2 \%$ & 0.1 \\
\hline PUNTO $3 \mathrm{a}$ & $8 \%$ & 0.4 \\
\hline
\end{tabular}


show the results that confirm the importance of our study. The first two tables show the results gathered in the measurement campaign carried out through analyzing the average internal temperature. Also, the relative humidity is calculated locally in spots identified inside buses, first with the bus in gear with closed doors, then with the bus at a stop with open doors. In both phases the system is on.

The following tables show the gap between experimental and simulated values implementing the same measure conditions. These gaps obtained through analysis and comparison of the thermo fluid dynamic features are sufficiently low, so the model is able to compare, in a subsequent stage, the different types of systems. Analyzing the different phases of bus usage, (in gear, immobile and at stops) it is possible to evaluate the conditioning issue related to pollution. In the summer time in large cities this becomes a crucial issue. The model built through technical schemes (compartment of the vehicle and the Thermo King), was obtained through collaboration with Irisbus. It has simulated a most unfavorable situation in passenger comfort, which is related to the substantial thermo

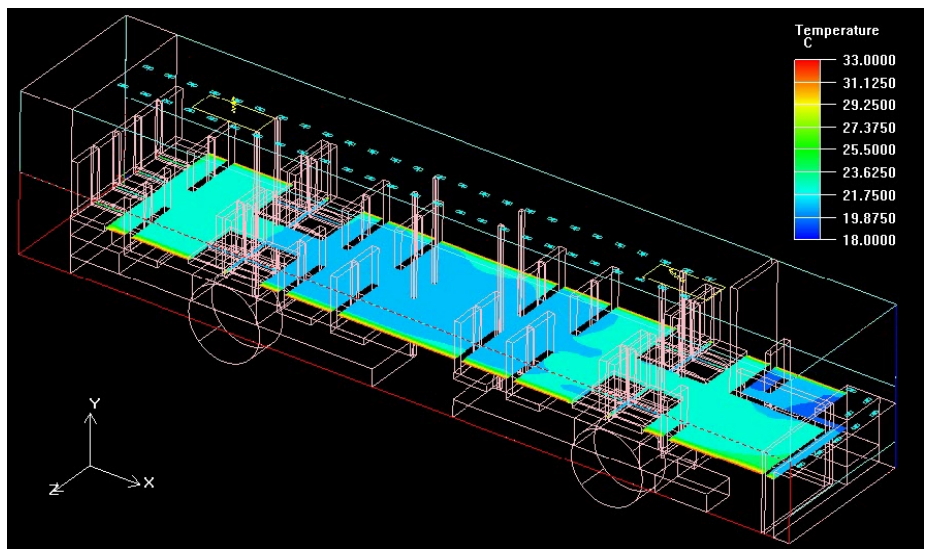

Figure 1: In gear phase temperature at 1,25 $\mathrm{m}$ above the floor.

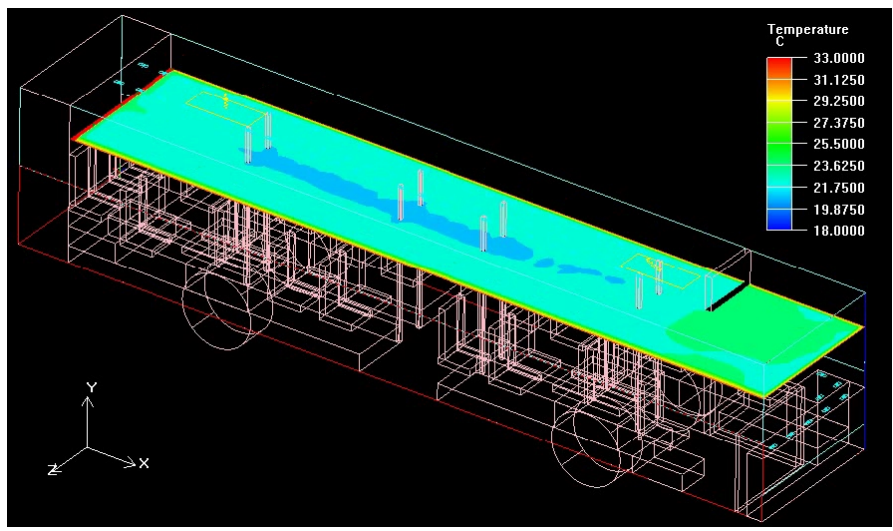

Figure 2: In gear phase temperature at 1,75 $\mathrm{m}$ above the floor. 
hygrometric changes that take place in the transition and stop. The opening and closing of the doors for 30 seconds substantially change the internal thermo fluid dynamic conditions by creating strong air speed and temperature gradients. These have an impact on passenger comfort especially in some areas of the vehicle. Figures 1-4 show the distribution of temperature in the two analyzed levels, thus monitoring the existence of possible temperature gradients. The figures clearly show that the thermo fluid dynamic gradients are generated, in the transitional phase by the opening/closing of the doors, with substantial differences within the same phase. This is due to the gradients created among different levels in the study (1.25 $\mathrm{m}$ seated passengers, $1.75 \mathrm{~m}$ standing passengers). These gradients have a much greater influence if the two different phases are compared.

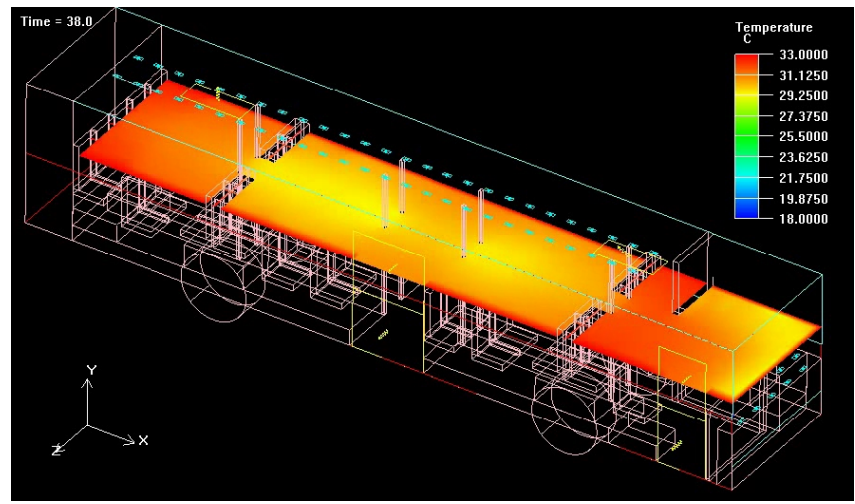

Figure 3: Halt phase temperature at 1,75 $\mathrm{m}$ above the floor.

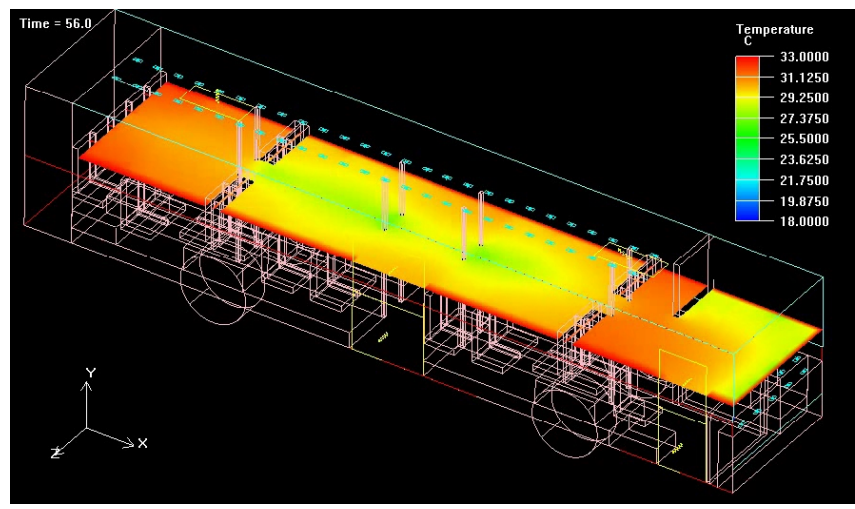

Figure 4: Halt phase temperature at 1,25 $\mathrm{m}$ above the floor.

\section{Air screened doors}

Having assessed the problems in the case of doors opening to let passengers in and out, with strong thermo fluid dynamic gradients, an interesting solution has 
been analyzed. Having seen the results, it gives the right hints in encourages further research and also a field study. The solution foresees the usage of air screened doors. An air screen properly installed generates, in correspondence with an opening, an invisible air screen. It avoids the air flows across the door, which reduces the heat exchange between the inside and the outside of the conditioned bus. Almost all the barrier models on the market can be equipped with thermic exchange batteries for the heating or cooling of the treated air. This is in order to reach and maintain those environmental conditions that guarantee the physical and psychological wellbeing of the occupants. This kind of usage transforms the air barrier from a simple separation element between the external and the internal environment, to a system component of thermo hygrometric control of the internal room. The study analyzes in depth, the relationship between the limited environment, which we want to maintain, and the external environment.

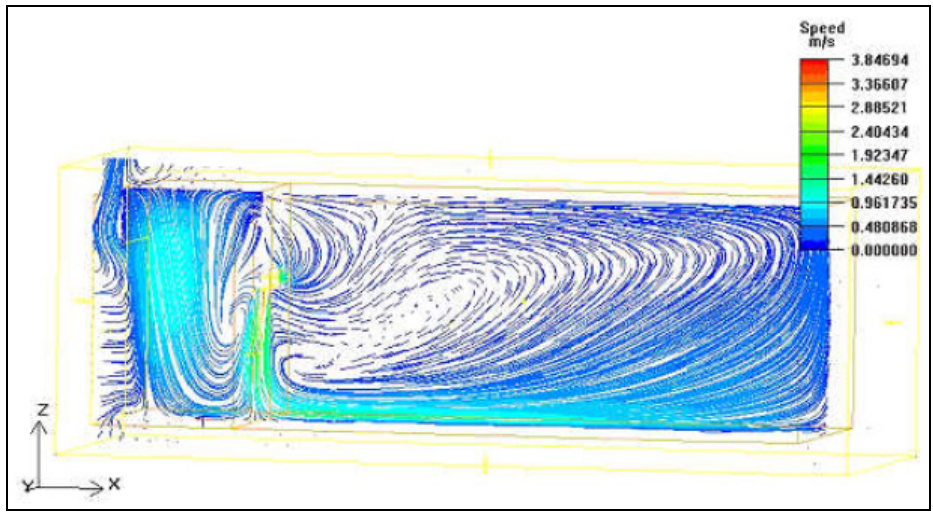

Figure 5: $\quad$ Fluid dynamic scheme of an air screened door.

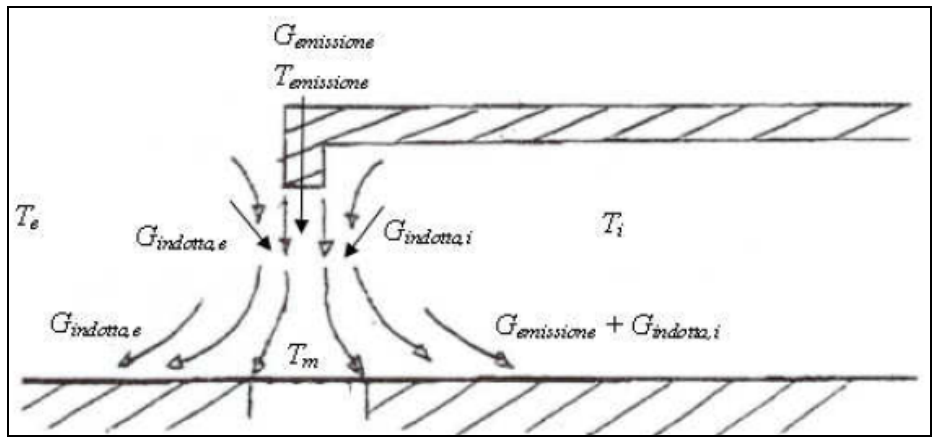

Figure 6: $\quad$ Air screened door design. 
By installing air screened doors or air barriers at the top of an entrance space, the heat leakages of the heating system through the opening of the doors are reduced, often in optimal conditions, by $70-90 \%$. The same air screened doors find their best application also during the summer time, reducing the leakages of fresh air from conditioned rooms with high energy savings. The air screened doors can also be equipped with onboard resistance for the air heating in the winter time or with hot water batteries in order to use the same heating circle for the same purpose. Furthermore, using the air barriers would allow environmental protection from the trespassing fumes, particles and insects, thus keeping the room air fresh and clean. The installation of the air barriers is extremely simple, and would not require structural changes of the vehicle.

\section{Thermo fluid dynamic study of the proposed solution}

The solution described above, has been simulated through the model previously built in order to evaluate the present thermo fluid dynamic conditions; furthermore, the thermic comfort benefits that can be guaranteed by a passenger air screened door system have also been studied.

The comparison between the present figure and the one described previously was performed through the implementation of the same side conditions. Some elements have been added to the models defined above. These elements satisfactorily simulate the air screened doors with the purpose of guaranteeing thermal insulation in situations such as the halting of the bus, which would otherwise be considered a real problem.

Once the technical thermo fluid dynamic specifications are known of the air screened doors currently on the market, it will be possible to test new solutions and analyze the benefits obtained.

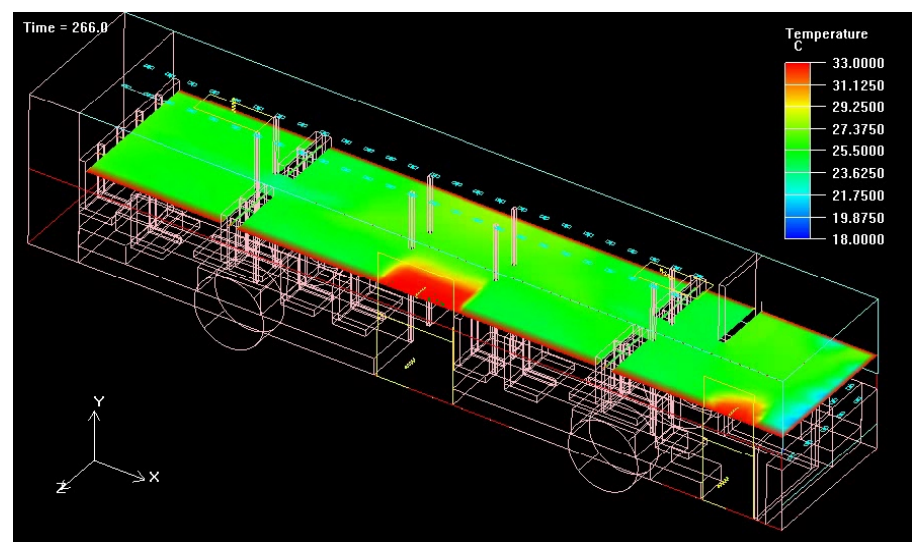

Figure 7: Halting phase with open doors at present conditions and with conditioning system on. 
Figures 7 and 8 clearly show optimization of the air distribution inside the compartment of the vehicle. The high internal thermo fluid dynamic homogeneity is evident. It is a significant improvement in internal comfort, even in the areas close to the doors that are the most uncomfortable.

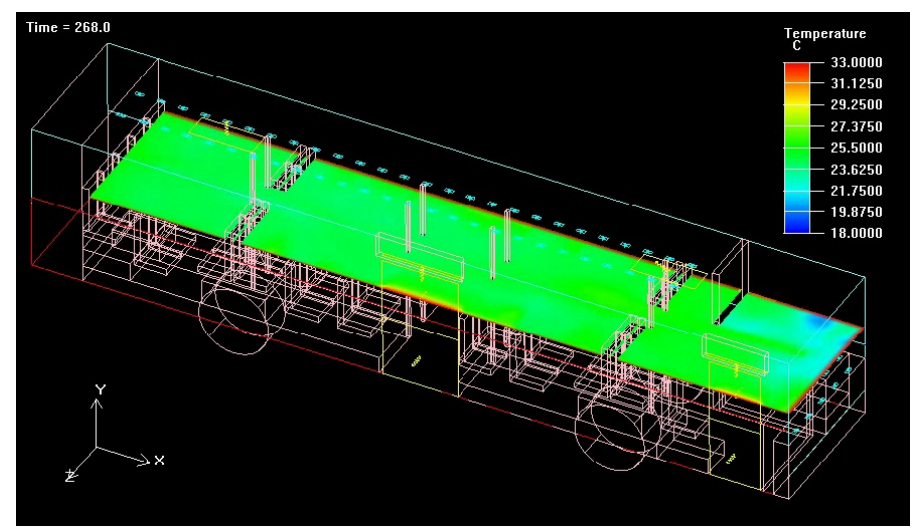

Figure 8: Halting phase with open doors, conditioning system on and with innovative air screened doors.

\section{Conclusions}

This work has reported the results of a two year study on the level of comfort inside transport means. The thermo hygrometric situation inside these means has been profoundly analyzed, observing the problems, whilst studying and simulating the various innovative system solutions, such as the air screened doors.

The results obtained and briefly mentioned have led to success. They have given the possibility to continue through the following stages of this research, into a field study of the proposed solution.

\section{References}

[1] Taniguchi Y, Aoki H, Fujikake K, Tanaka H, Kitada M (1992) Study on car air conditioning system controlled by car occupants' skin temperatures-part 1: Research on a method of quantitative evaluation of car occupants' thermal sensations by skin temperatures. SAE Paper Ser 920169: 13-19(1992)

[2] Daniels, R. e Henser, D. (2000), "Valuation of environmental impacts of transport projects", Journal of transport economics and policy, 34 (2), 189-214.

[3] Franceschinis, B. (2002), Inquinamento atmosferico e patologia asmatica: uno studio di analisi congiunta, tesi di laurea in Economia e Trasporti, relatore Prof. Romeo Danielis, Facoltà di Economia, Trieste. 
[4] DM 20 marzo 2000: "Caratteristiche tecniche delle emulsioni di olio da gas ed olio combustibile denso con acqua destinate alla trazione ed alla combustione".

[5] APAT, Annuario dei Dati Ambientali, Edizione 2002.

[6] ANPA, CTN-ACE, Manuale dei fattori di Emissione Nazionale, 2002.

[7] Legge 9 gennaio 1991, n. 10: "Norme per l'attuazione del Piano energetico nazionale in materia di uso razionale dell'energia, di risparmio energetico e di sviluppo delle fonti rinnovabili di energia

[8] Fonte UNIONE EUROPEA DG XI

[9] Rapporto EUR 13854 EN - 1992

[10] ASHRAE. Handbook Fundamentals 2001. Space Air Diffusion, Atlanta: American Society of Heating, Refrigerating and Air Conditioning Engineers.

[11] Bruun H.H. Hot-wire anemometry. Principles and signal analysis. Oxford University Press 1995, New York.

[12] Chen Q., Moser A. 1991. Simulation of a multiple nozzle diffuser. Proceedings of the 12th AIVC Conference, Vol.2, pp.1-14

[13] Chow W.K., Wong L.T. 1997. Design of Air Diffusion Terminal Devices in Passenger Train Vehicle. Journal of Environmental Engineering, 1997, pp.1203-1207

[14] EN 13129-1. Railway applications - Air Conditioning for main line rolling stock - Part.1: Comfort parameters.

[15] Etheridge D., Sandberg M., 1996. Building Ventilation. Theory and Measurements. John Wiley \& Sons, Chichester, 1996 pp.391-446.

[16] Fanger P.O., Melikov A.K., Hanzawa H. and Ring J.1988. Air Turbulence and Sensation of Draught. Energy and Buildings, vol. 12 (1998) pp. 21-39

[17] S. Grignaffini, A. Vallati. Design of Air Distribution System in A Train Coach Dedicated To Sick Persons. Proceedings of the Roomvent 2002 Air Distribution in Rooms. Eighth International Conference. Copenhagen Denmark 8-11 September 2002.

[18] S. Grignaffini, A. Vallati. Experimental And Numerical Studies On Air Diffusion In A Single Office. Proceedings of the 9th International Conference on Indoor Air Quality and Climate. Monterey, California June30-July5, 2002 pp.308-313.

[19] ISO Standard 7730, Moderate thermal environments-determination of the PMV and PPD indices and specification of the conditions for thermal comfort. International Standards Organization (1997). 